Research Article

\title{
The Influence of Pile-Driving Vibration on the Soil Nailing Support of a Silty Soil Foundation Pit
}

\author{
Yuancheng Guo $\left(\mathbb{D},{ }^{1}\right.$ Hao $W u\left(\mathbb{D},{ }^{1}\right.$ and Chenglin $\mathrm{Li} \mathbb{D}^{2}$ \\ ${ }^{1}$ School of Civil Engineering, Zhengzhou University, Zhengzhou 450001, China \\ ${ }^{2}$ Institute of Geotechnical Engineering, Southeast University, Nanjing 210096, China \\ Correspondence should be addressed to Hao Wu; wu_hao2020@gs.zzu.edu.cn
}

Received 24 December 2020; Revised 15 March 2021; Accepted 23 April 2021; Published 19 May 2021

Academic Editor: Antonello Troncone

Copyright (C) 2021 Yuancheng Guo et al. This is an open access article distributed under the Creative Commons Attribution License, which permits unrestricted use, distribution, and reproduction in any medium, provided the original work is properly cited.

\begin{abstract}
The ground vibration induced by pile driving affects the safety of the adjacent foundation pit. In this paper, the influence of pile-driving vibration on the soil strength and the nail-soil interface strength was studied, and the variation in the axial force and displacement of the soil nail under vibration was analyzed. The paper studied the effects under different vibration parameters on the soil strength and the nail-soil interface strength by using a vibration exciter and a nail pull-out model box. The results showed that the stronger the excitation force was and the higher the frequency was, the greater the attenuation of the soil strength and nail-soil interface strength was. On the contrary, the change of the internal friction angle of the soil was not obvious under the vibration. The nail-soil interface strength recovered when the vibration terminated. Decreases in $c$ and $\tau_{p}$ led to an increase in the working length of the soil nail, a redistribution of the axial force, and an augmentation in the soil nail displacement.
\end{abstract}

\section{Introduction}

Soil nails are slender metal bars placed in the soil to stabilize soil masses, such as cut and fill slopes, deep excavations, and tunnels. Since soil nails were developed, they have been increasingly used in various fields due to their technical and economic advantages. In recent years, the number of urban high-rise buildings has increased substantially. During foundation pit construction, the pile-driving vibration has a significant impact on the soil nailing support of the foundation pit, threatening the stability and safety of the foundation pit.

In cities, pile-driving vibration produces noise, disturbs the environment, and destroys the adjacent structures. Many studies have shown that pile-driving vibration often leads to the destruction of adjacent structures [1] either directly or indirectly due to soil settlement. The paper in [2] discusses the types of piles and soil conditions, where the negative effects of high rebound on the performance of the hammer system, pile, and soil have been observed, and a case history where field instrumentation and testing were performed. In [3], a three-dimensional finite element approach is used to analyze the response of reinforced concrete flexible piles to inclined loads. There are few studies on the ground vibration induced by pile-driving and its impact on adjacent structures and foundation pits [4]. In most papers, an axisymmetric finite element model was established to simulate the piling process. Axisymmetric finite element analysis can be used to predict the impact of hammering [5] or different piling methods are used to study the impact on the surrounding soil [6]. Henke et al. [7] used the three-dimensional finite element method to evaluate the impact of piling on adjacent buildings and compared the impact of static pile-driving and vibration driving on the surrounding soil. Henke [8] analyzed the main influencing factors of pile-driving on adjacent structures using the finite element method.

The stability of the soil nailing support under a vibration load is a research hotspot in geotechnical engineering, especially in expressway slopes and earthquake areas. Many studies were conducted on slope vibration stability and the deformation, as well as dynamic response characteristics domestically and internationally. Li et al. [9] proposed an improved method for calculating the seismic displacement 
of a slope supported by soil nails under an earthquake. Some researchers [10, 11] analyzed the safety of soil nailing support structures under seismic loads. Some scholars also investigated the dynamic response of structures for different support configurations and assessed the influence of the amplitude of acceleration above $0.4 \mathrm{~g}$ on the soil nailing support using model tests [12, 13]. Zhu et al. [14] analyzed the cumulative effect of the axial force of the soil nails, the panel displacement and acceleration, and the settlement of the surface under a cyclic load. Few studies were conducted on the deformation and stability of the soil nailing support system under a vibration load, since these studies are limited to numerical calculations [15-17]. Experimental studies primarily focused on tunnels $[18,19]$. However, there are few studies on the interaction between the supporting structure and the soil slope under vibration. Li [20] analyzed the dynamic response and interaction of the soil slope and the anchor structure under an earthquake.

Previous studies on the impact of a vibration load on the soil nailing support focused mostly on the dynamic response and permanent deformation of the soil nailing support, without considering the effect on the soil strength and the nail-soil interface interaction under a vibration load. However, in practical engineering projects, the vibration load of long-time pile-driving lasting influences these two aspects. In this study, a model test is used to analyze the influence of pile-driving vibration on the soil behavior and nail-soil interface strength under different vibration conditions. The effects of the soil nail axial force and displacement after the variation of soil strength and nailing interface strength is investigated.

\section{Model Test Materials and Equipment}

\subsection{Model Test Materials}

2.1.1. Fundamental Physical and Mechanical Properties of the Soil. The soil used in the test was silt from a foundation pit in eastern Zhengzhou, Henan province. Following the standard for the soil test method [21], the particle size distribution was determined by sieving and the use of a densitometer. Multiple groups of parallel tests were carried out; the test results are shown in Table 1 and Figure 1.

The silt was first dried and ground for screening. The size of the sieve holes was $5 \mathrm{~mm}$. The physical parameters of the silt are listed in Table 2.

As shown in Table 2, the dry density of the undisturbed soil was $1.65 \mathrm{~g} / \mathrm{cm}^{3}$, and the maximum dry density was $1.87 \mathrm{~g} / \mathrm{cm}^{3}$. The dry density of the silt in the model box was the same as that of the undisturbed soil $\left(1.65 \mathrm{~g} / \mathrm{cm}^{3}\right)$. The compactness was 0.88 , and the moisture content was $13 \%$, which was close to the optimal moisture content. A quick shear test was carried out on the soil in this condition; $c$ was $27.6 \mathrm{kPa}$ and $\varphi$ was $27.8^{\circ}$.

2.1.2. Model Nail. At present, most of the model tests related to the soil nail pullout are conducted at a small scale due to the limitations of the test conditions and other factors. These conditions do not adequately describe the shear behavior of the interface between the soil and the nail. In practical
TABLE 1: Soil particle size distribution.

\begin{tabular}{lccccc}
\hline Particle size $/ \mathrm{mm}$ & $>0.1$ & $0.075 \sim 0.1$ & $0.05 \sim 0.075$ & $0.01 \sim 0.05$ & $<0.01$ \\
Percent fine $/ \%$ & 17.9 & 11.8 & 56.8 & 8.5 & 5 \\
\hline
\end{tabular}

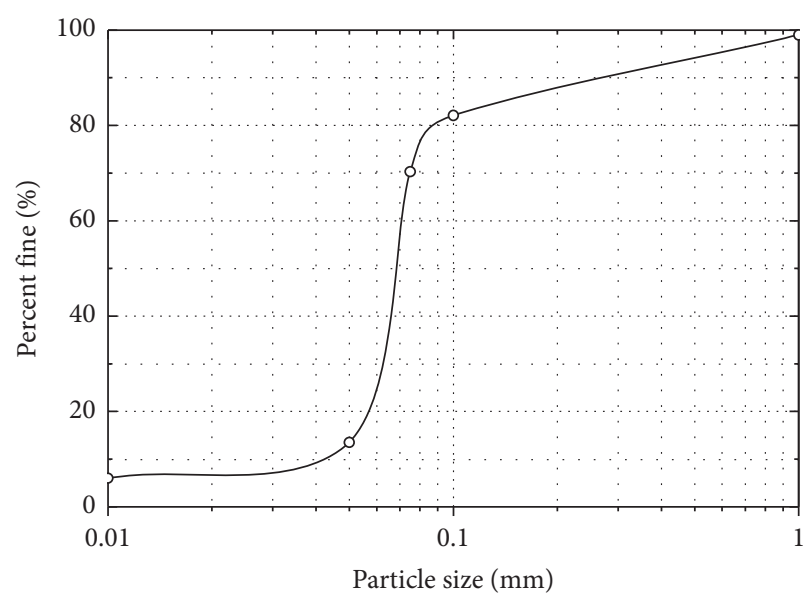

FIgure 1: Particle size distribution of the silty soil.

TABLe 2: Physical parameters of the silty soil sample.

\begin{tabular}{lc}
\hline Dry density of undisturbed soil, $\mathrm{g} / \mathrm{cm}^{3}$ & 1.65 \\
Maximum dry density, $\mathrm{g} / \mathrm{cm}^{3}$ & 1.87 \\
Optimum moisture content \% & 13.4 \\
Liquid limit \% & 24.4 \\
Plastic limit \% & 15.3 \\
Plasticity index & 9.1 \\
\hline
\end{tabular}

engineering, the diameter of the soil nail drilling hole is about $100 \mathrm{~mm}$, and HRB400 steel bars with a diameter of $18 \mathrm{~mm} 25 \mathrm{~mm}$ are usually used and formed by cement slurry grouting with a water-cement ratio of 0.5 . Therefore, the elastic modulus of the soil nail is about $20 \mathrm{GPa}$. Based on modulus equivalence and practicability of the test, a hollow aluminum pipe [22] was used as the nail material in this test. The pipe had a length of $600 \mathrm{~mm}$, an external diameter of $100 \mathrm{~mm}$, and a thickness of $8 \mathrm{~mm}$, as shown in Figure 2. The contact length between the nail and the soil was $400 \mathrm{~mm}$. The sand was glued to $410 \mathrm{~mm}$ of the nail surface to increase the roughness.

\subsection{Test Equipment}

2.2.1. Vibration Exciter and Parameter Setting. Pile-driving vibrations are complex, and the vibration generates compression waves, shear waves, and surface waves in the soil around the pile. The surface waves are Rayleigh waves. Rayleigh waves account for two-thirds of the total energy from the vertical vibration source and are the dominant wave type in the vibration of structures or foundation pits located at or near the ground [23]. Since the experiments were conducted under laboratory conditions, the paper simplified the pile-driving vibration load and only considered the influence of Rayleigh waves on the pullout force of the nail. The TROMINO vibration acquisition instrument was used to collect the vibration data. 


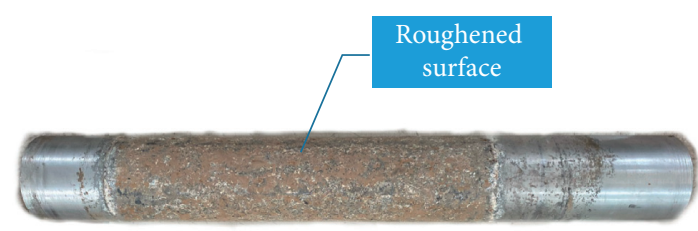

FIgUre 2: Model nail.

A vibration exciter was selected to simulate the piledriving vibrations. The vibration exciter type was a $380 \mathrm{~V}$ asynchronous vibration motor, as shown in Figure 3. The excitation force was generated by the eccentric vibrator in the motor rotating around the central axis, causing ground vibration that propagated to the soil in the model box. The magnitude of the excitation force was changed by adjusting the angle between the two rotors and the vibration frequency was adjusted by the frequency converter. The paper used equation (1) to calculate the excitation force using the angle of the rotor:

$$
F=4 \pi^{2} m f^{2} r_{\max } \sin \frac{180-\theta}{2}
$$

where $F$ is the excitation force; $m$ is the mass of the rotors; $f$ is the vibration frequency; $r_{\max }$ is the distance between the center of gravity of the rotor and the center of the circle when $\theta$ is $0^{\circ}$; and $\theta$ is the angle between the center lines of the rotors.

Examples of pile-driving vibration data of a foundation pit are listed in Table 3, and the acceleration time-history curve is shown in Figure 4. The data show significant vibration generated by pile-driving. The main frequency of environmental vibration is $5 \sim 40 \mathrm{~Hz}$, the peak frequency is about $10 \mathrm{~Hz}$, and the amplitude of acceleration is less than $0.1 \mathrm{~g}$.

Equation (1) indicates that the excitation force is related to the rotation frequency of the rotor. The magnitude of the excitation force also affects the magnitude of the vibration acceleration. There is a linear correlation between the excitation force and the acceleration. Based on the vibration frequency and acceleration obtained from field measurements and the vibration data collected in the laboratory before experiment, the maximum excitation force was set at $8 \mathrm{kN}$, and the maximum vibration frequency was set at $10 \mathrm{~Hz}$.

2.2.2. Model Test Box. Since the box has a boundary effect and the influence range of the soil nail pullout test is unknown, the specification was used as a reference. The influence range was set to 6 times the pile diameter, the height was $850 \mathrm{~mm}$, and the width was $600 \mathrm{~mm}$. The volume of soil should not be too large to ensure that the vibration of the soil in the box is consistent and the soil reaches the on-site acceleration amplitude under excitation; thus, the length of the box was $400 \mathrm{~mm}$. The inner dimension of the box was $400 \mathrm{~mm} \times 600 \mathrm{~mm} \times 850 \mathrm{~mm}$ (length $\times$ width $\times$ height), and the box had no bottom, as shown in Figure 5. The box walls

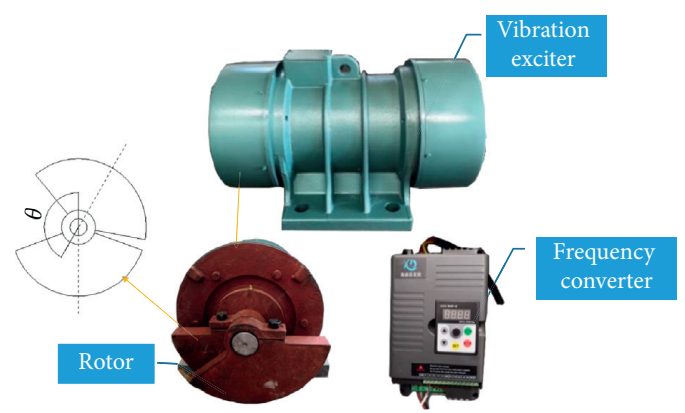

Figure 3: The vibration exciter equipment.

TABle 3: Pile-driving vibration data of a foundation pit.

\begin{tabular}{lccc}
\hline & X-acceleration $(\mathrm{g})$ & $\begin{array}{c}\text { Y-acceleration } \\
(\mathrm{g})\end{array}$ & $\begin{array}{c}\text { Z-acceleration } \\
(\mathrm{g})\end{array}$ \\
\hline Piling/+ & 0.0659 & 0.248 & 0.082 \\
Piling/- & -0.083 & -0.119 & -0.0919 \\
Normal/+ & 0.0018 & 0.0024 & 0.0056 \\
Normal/- & -0.0022 & -0.0015 & -0.0042 \\
\hline
\end{tabular}

consisted of high-strength steel plates with $6 \mathrm{~mm}$ thickness, and $120 \mathrm{~mm}$ round holes were drilled on both sides of the box for the nail. During the test, rubber sealing rings were used to seal the gap between the holes and the nail. The box wall was lined with plastic film to reduce the friction between the wall and the soil. A steel ruler was welded inside the box to measure the soil compactness, soil settlement, and displacement caused by the vibration.

Two hydraulic jacks with pressure compensation devices were placed between the bearing plate and the reaction frame to provide the vertical load. The vertical stress was measured by earth pressure cells placed on both sides of the nail. The horizontal force was provided by a through-bore jack, which was connected to the screw rod with nuts. The screw rod passed through the nail and was attached to the nail with gaskets and nuts. The pullout force was determined by the bolt drawing instrument. The layout of the test equipment is shown in Figure 6.

The earth pressure cells were placed on both sides of the soil nail. A displacement meter was located at the end of the nail, as shown in Figures 7 and 7 (a) CM-2B static data acquisition instrument was used to collect the data.

\section{Laboratory Test Description}

The test was divided into two parts: a test of the soil mechanical parameters and a test of the nail pullout force. The results of nonvibration and vibration tests were compared to study the influence of different excitation forces and excitation frequencies. In this study, the paper improved the soil nail loading scheme. A horizontal force was applied using a bolt drawing instrument for loading at different stages $(0.1 \mathrm{kN}$ at each stage).

(1) Soil nail pullout test and soil mechanical parameter test without vibration. 

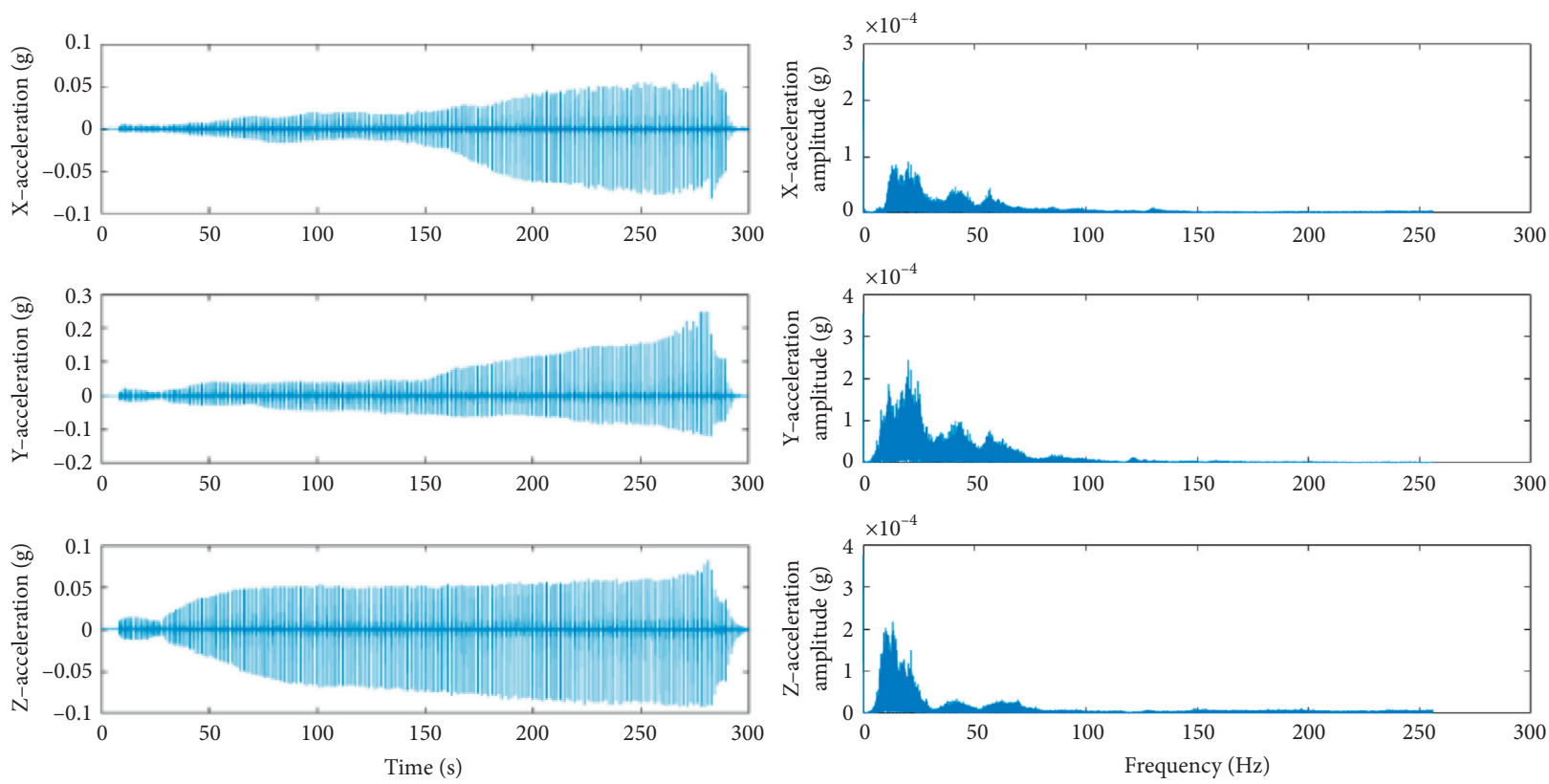

Figure 4: Acceleration time-history curve and amplitude spectrum.

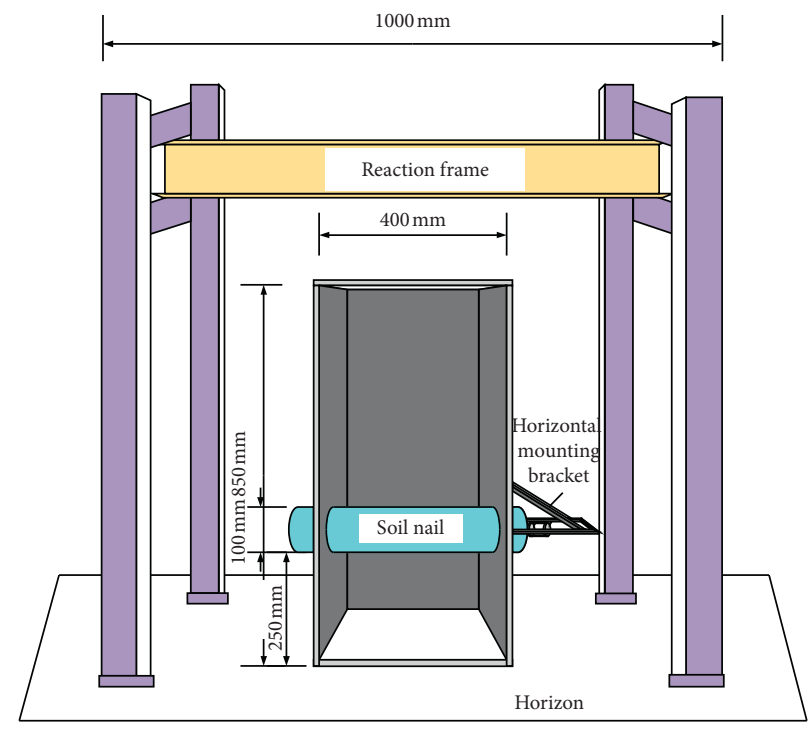

FIGURE 5: Schematic diagram of the model box.

(1) Measuring the friction between the soil nail and the box.

(2) Soil filling: the soil had been crushed, dried, and passed through a $5 \mathrm{~mm}$ sieve. After reaching a soil moisture content of $13 \%$, the soil was placed in sealed bags or boxes for two days. The model box was filled in layers from bottom to top; the layer thickness was $10 \mathrm{~cm}$ or $15 \mathrm{~cm}$, and the total height was $80 \mathrm{~cm}$. The dry density of each soil layer was $1.65 \mathrm{~g} / \mathrm{cm}^{3}$, representing $88 \%$ compaction.

(3) Waiting for soil stabilization: after filling the box with soil, the test waited two days.

(4) Soil nail pullout test: after the soil was stable, the nail was step-loaded using the anchor drawing instrument. A pullout force of $0.1 \sim 0.2 \mathrm{kN}$ was applied each time, and the pullout force $F$ of the soil nail was recorded. Finally, the friction between the nail and the box body was subtracted.

(5) Soil sampling: soil samples were obtained with a wire saw. Three soil samples were obtained in each group, and the soil strength parameters $c$ and $\varphi$ were obtained from a triaxial shear test (shearing process: the confining pressures of the soil samples in the triaxial tests were $100 \mathrm{kPa}$, $150 \mathrm{kPa}$, and $200 \mathrm{kPa}$, respectively, and the shear rate was $0.5 \mathrm{~mm} / \mathrm{min}$; the test was finished when the axial strain reached $20 \%$ ). 


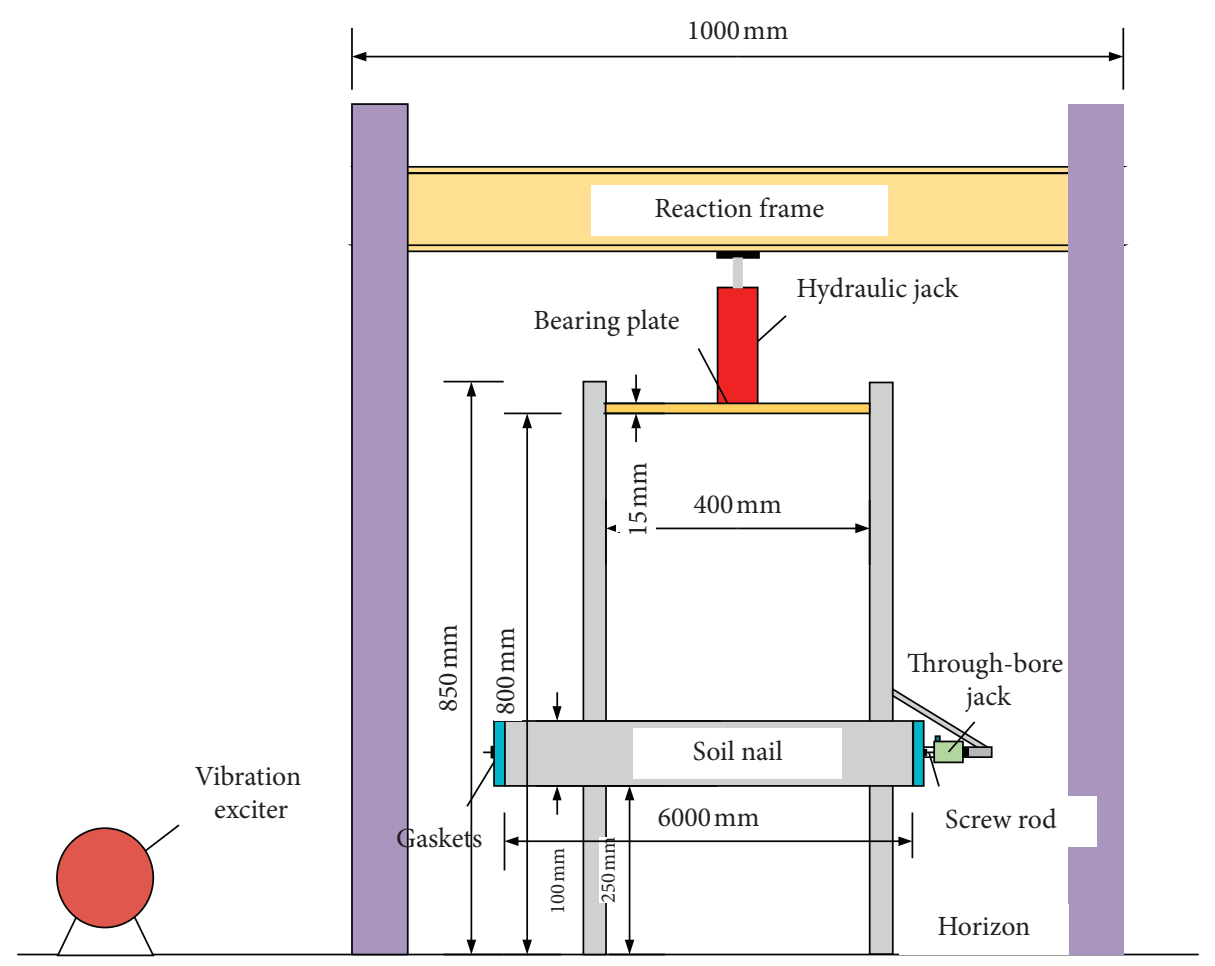

(a)

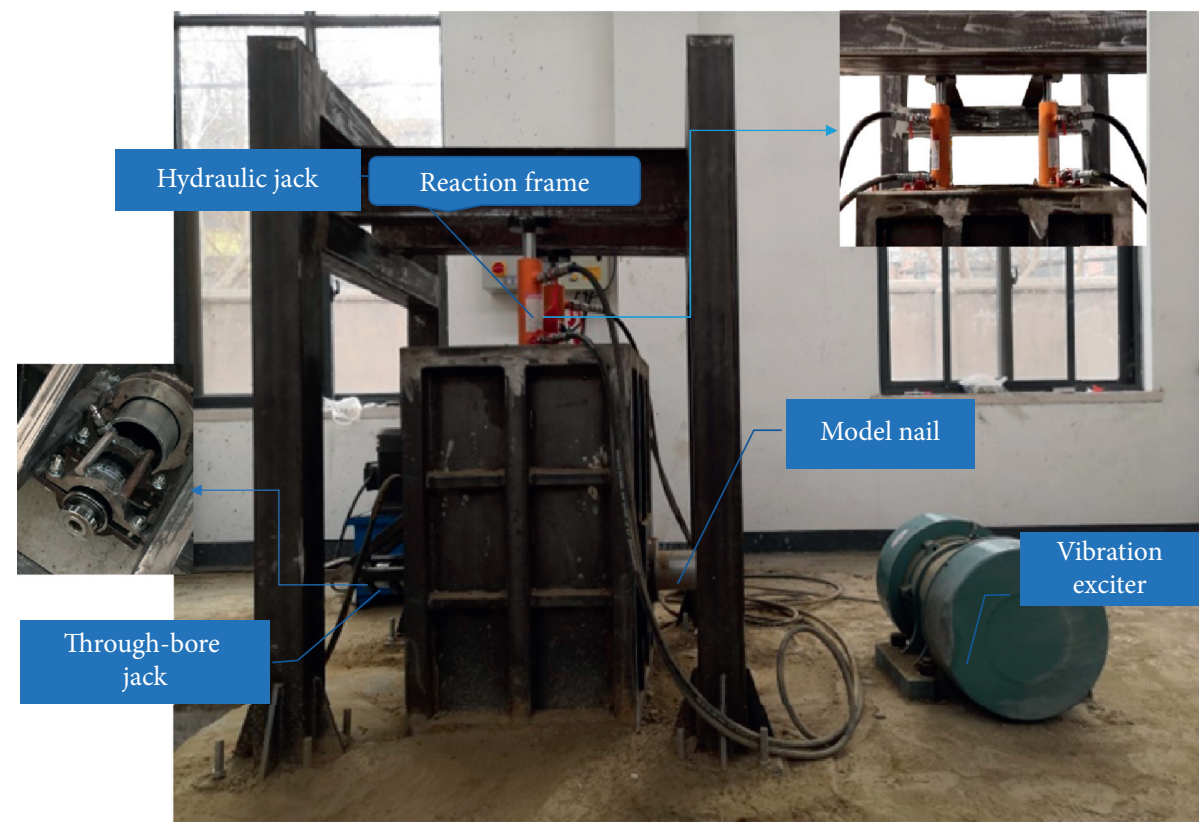

(b)

Figure 6: Layout of model test. (a) Schematic diagram. (b) Test photograph.

(2) Soil nail pullout test and soil mechanical parameter test with vibration.

Steps (1) to (3) were the same as in the test without vibration.

(4) Vibration loading test: after the soil was stable, a preforce that was slightly smaller than the static pullout force $F$ was applied to the end of the nail, and the vibration load was applied by the vibration exciter. For each change of $0.1 \mathrm{kN}$, the corresponding time and force $F_{n \text {-during }}$ were recorded. For comparison with $F_{n \text {-during, the }}$ measurement method of $F_{n \text {-after }}$ was as follows: according to the total time of $F_{n \text {-during, it was }}$ divided into ten minutes as a unit, and $F_{n \text {-after }}$ was recorded once after the vibration stopped. For example, $F_{n \text {-during }}$ regained equilibrium state at 

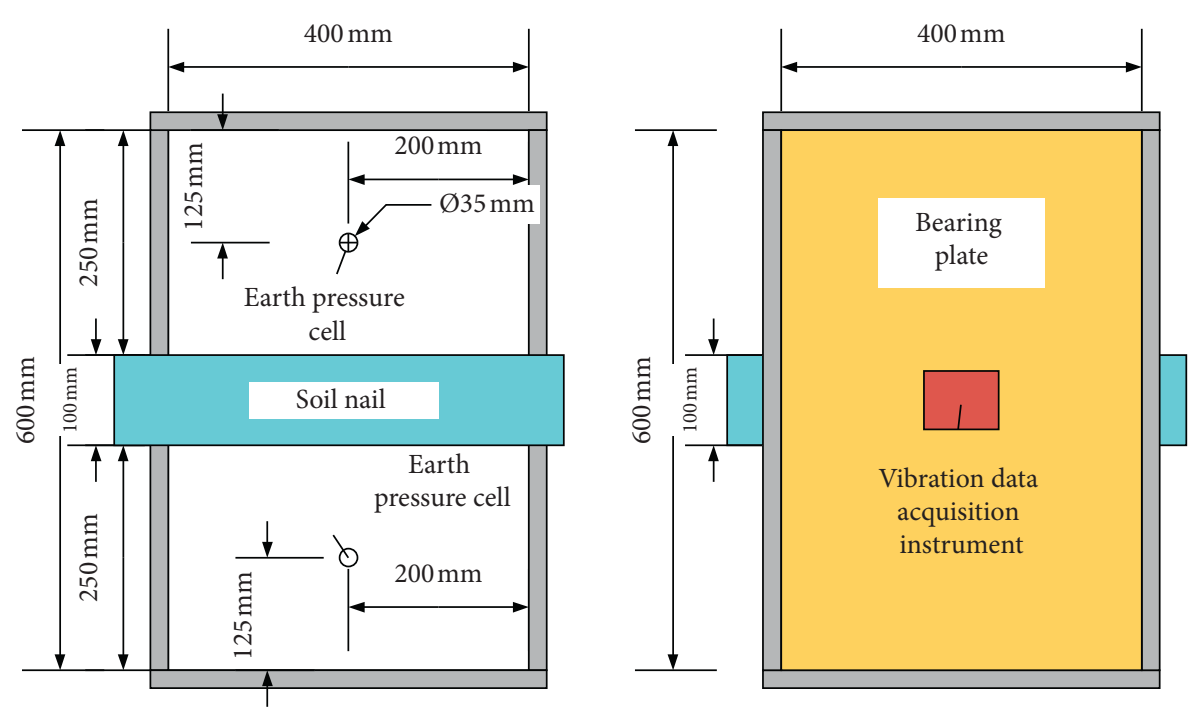

(a)
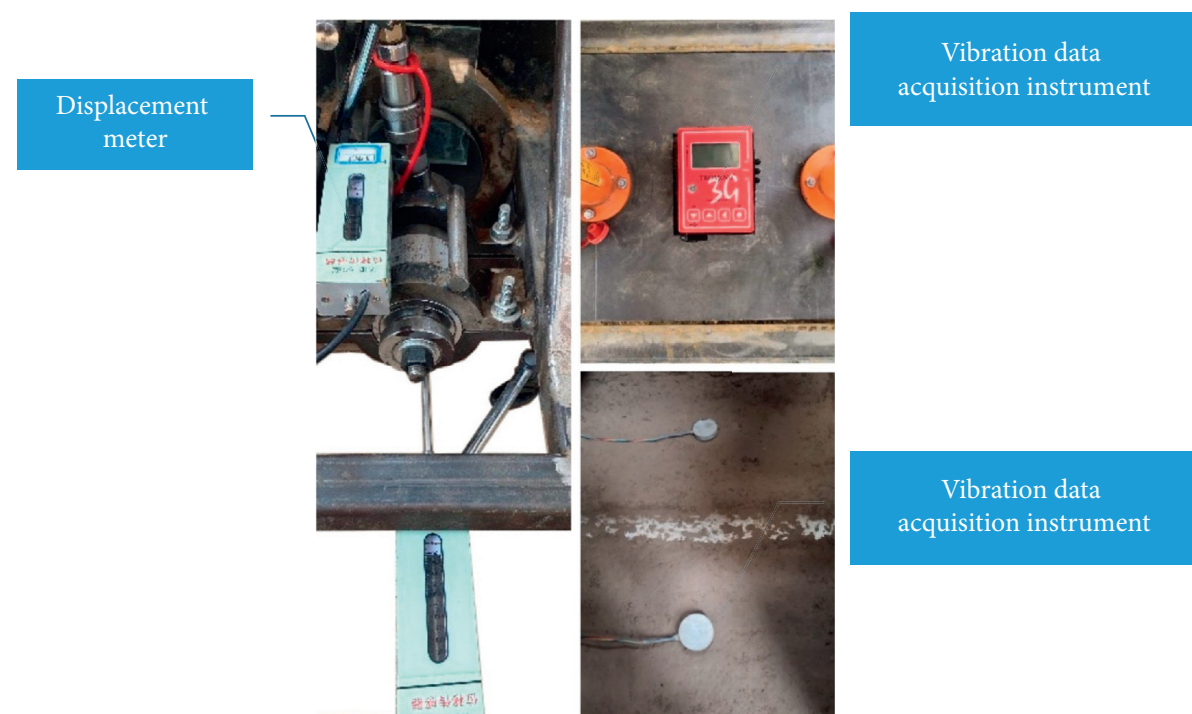

(b)

FIgURE 7: Layout of data measuring instruments. (a) Schematic diagram. (b) Test photograph.

fifty minutes under vibration excitation, and the excitation time of $F_{n \text {-after }}$ was divided into $10 \mathrm{~min}, 20 \mathrm{~min}, 30 \mathrm{~min}, 40 \mathrm{~min}$, and $50 \mathrm{~min}$. Then record $F_{n \text {-after }}$ after vibration stopped, respectively.

(5) Soil sampling: the steps were the same as in the test without vibration.

Table 4 shows the different test working conditions under the overburden pressure of $80 \mathrm{kPa}$.

\section{Analysis and Results}

4.1. Influence of Excitation Vibration on Soil Strength. Unconsolidated-undrained (UU) triaxial tests (GDS system) were carried out on the soil samples exposed to vibration and no vibration, and the strength parameters were compared. The confining pressures were 200,150 , and $100 \mathrm{kPa}$ (left to right (same hereafter), Figure 8). The eight subfigures in Figure 8 corresponded to the soil samples under eight test conditions in Table 4.

As shown in Figure 8, in the triaxial test, the soil samples not exposed to vibration did not exhibit a shear failure area. The soil samples exposed to vibration with lower excitation and frequency had a small shear failure area under low confining pressure, and those exposed to vibration with higher excitation and frequency all had significantly shear failure areas for different confining pressures. This result indicated that the strength of the soil was changed by the vibration.

Because the macroscopic failure types of the soil under different vibration conditions were relatively similar, the paper only compared the failure types of the nonvibration and vibration soil samples under condition 5, as shown in Figure 9.

The soil samples exposed to vibration had more significant damage than the samples not exposed to vibration, 
TABLE 4: Test working conditions.

\begin{tabular}{|c|c|c|}
\hline Number & Excitation force $(\mathrm{kN})$ & Vibration frequency $(\mathrm{Hz})$ \\
\hline 1 & - & - \\
\hline 2 & 2 & 6.7 \\
\hline 3 & 4 & 6.7 \\
\hline 4 & 6 & 6.7 \\
\hline 5 & 8 & 6.7 \\
\hline 6 & 4 & 5 \\
\hline 7 & 4 & 8.3 \\
\hline 8 & 4 & 10 \\
\hline
\end{tabular}

* The overburden pressure of $80 \mathrm{kPa}$ was determined according to the overburden earth pressure of the actual engineering soil nails.

and the shear failure area was larger, and the cracks were deeper. Macroscopically, the soil strength was lower for the vibration samples. The triaxial shear data showed that the intercept cohesion was $26.9 \mathrm{kPa}$ (nonvibration samples) and $16.1 \mathrm{kPa}$ (vibration samples), and the internal friction angle was $27.4^{\circ}$ and $27.8^{\circ}$, respectively. The intercept cohesion was significantly reduced by vibration, whereas the internal friction angle changed only slightly. Table 5 lists the soil parameters under different conditions.

The comparative analysis of the soil strength parameters under different excitation forces is shown in Figure 10(a). As the excitation force increased, the soil intercept cohesion decreased significantly, whereas the internal friction angle changed only slightly. The decrease in soil intercept cohesion may be due to a change in compactness or structural damage caused by vibration. Therefore, the soil compactness before and after vibration was measured using a cutting ring. The data are listed in Table 5. It was found that the variation in compactness was only about $0.3 \%$; thus, it was concluded that the compaction before and after the vibrations was basically unchanged, and the soil strength was attenuation. In this paper, it was considered that the silt had a certain structure, and the vibration would damage the soil structure. The soil exposed to higher excitation forces exhibited greater strength attenuation.

As shown in Figure 10(b), the intercept cohesion decreased significantly, and the internal friction angle changed negligibly with an increase in the excitation frequency. The reduction in soil strength was attributed to soil structure damage. The soil structure damage was greater at higher vibration frequencies due to greater soil strength attenuation. The soil structure strength damage degree depends on the excitation force magnitude and frequency [24].

4.2. Influence of Vibration on the Interface Strength. Four groups of nail pullout tests with overburden loads of $80 \mathrm{kPa}$, $160 \mathrm{kPa}, 240 \mathrm{kPa}$, and $14 \mathrm{kPa}$ were conducted. The relation between the pullout force, shear stress, and displacement is shown in Figure 11.

The ultimate pullout force of the nail obtained from the test divided by the surface area of the nail is the ultimate friction resistance or the nail-soil interface strength $\tau_{p}$.

As shown in Figure 11, the ultimate pullout force of the nail increased with an increase in the overburden pressure $(\mathrm{OP})$, because the interaction between the silty soil and the interface increased, and the interface shear strength increases significantly. In the initial stage, the displacement increased linearly with an increase in the pullout force, indicating that the soil was compacted and had elastic properties. When the relative displacement between the nail and soil reached a certain value, the shear stress remained unchanged, the nail exhibited uniform displacement, and the soil experienced shear failure. When the OP was low, the peak shear stress was reached quickly. As the OP increased, the pullout displacement corresponding to the peak shear stress increased gradually. This result was consistent with the test results of Sukmak et al. [25] and Yin et al. [26].

The shear stress corresponding to the ultimate pullout force is the ultimate nail-soil interface strength. Assuming that the shear stress is uniformly distributed along the nail, the nail-soil interface strength $\tau_{p}$ is determined by equation (2) based on the soil nail pull-out test results [27, 28], as shown in Figure 12.where $T$ is the ultimate pullout force, $D$ is the diameter of the nail, $L$ is the length of the soil nail, and $\tau_{p}$ is the maximum shear stress (nail-soil interface strength).

$$
T=\pi D L \tau_{p}
$$

As shown in Figure 13, corresponding prepullout force was given to the end of the nail under the overburden pressure of $80 \mathrm{kPa}$, and the variation of the maximum pullout force was studied under different excitation forces. Figures 13(a) and 13(b) showed the variation trend of $F_{n \text {-during }}$ and $F_{n \text {-after }}$ under different excitation forces. Figure $13(\mathrm{c})$ showed the ratio of the change of $F_{n \text {-during }}$ and $F_{n-a f t e r}$ to the initial prepullout force, respectively, and the ratio of $F_{n \text {-after }}$ to $F_{n \text {-during. }}$

As shown in Figures 13(a) and 13(b), the pullout force exerted on the end of the nail gradually decreased with an increase of the vibration time, indicating that the nail-soil interface strength decreased. The greater the excitation force was, the larger the decrease rate was ( ${ }^{*}$ the force $2 / 4 / 6 / 8 \mathrm{kN}$ in Figures 13(a) and 13(b) was the excitation force calculated by equation (1)). The vibration amplitude was higher at higher excitation force, and the strength attenuation of the nail-soil interface increased. According to Figures 13(a) and 13(b), the pullout force did not decrease at a steady rate with an increase in the vibration time but gradually stabilized, indicating that the nail-soil interface strength decreased and reached an equilibrium state under the excitation force or vibration acceleration. The pullout force of the nail was higher after vibration than during vibration, demonstrating 

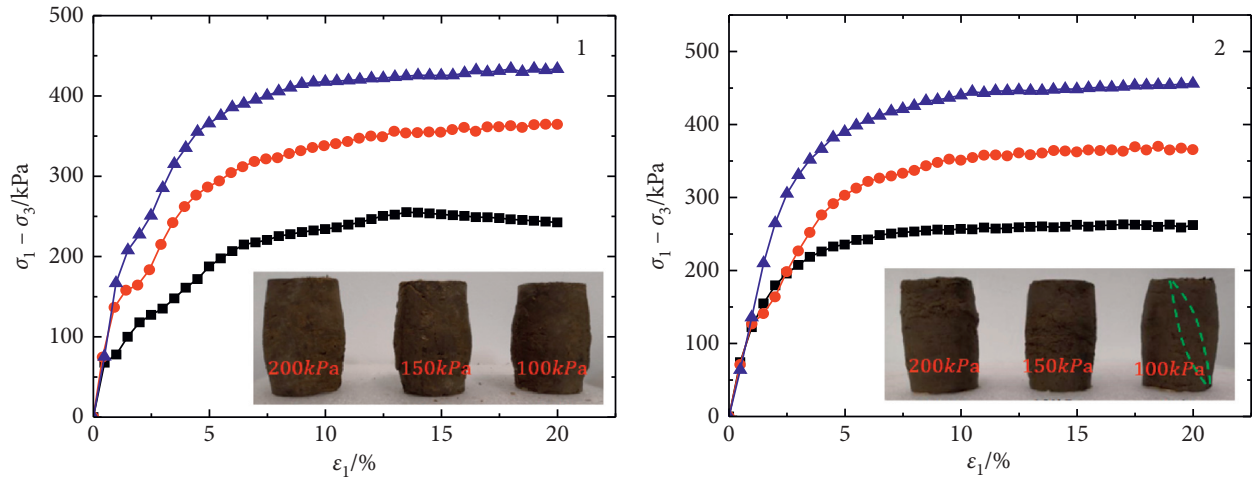

$-100 \mathrm{kPa}$
$\rightarrow-150 \mathrm{kPa}$

$\rightarrow 100 \mathrm{kPa}$

$-150 \mathrm{kPa}$

- $200 \mathrm{kPa}$
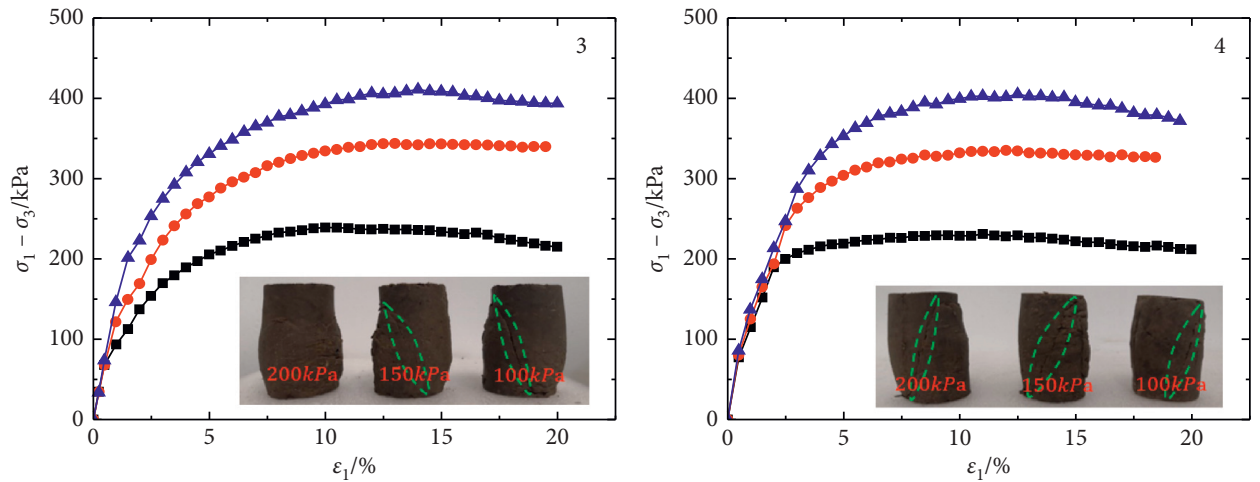

$\rightarrow-100 \mathrm{kPa}$

$\rightarrow 150 \mathrm{kPa}$

$\_200 \mathrm{kPa}$

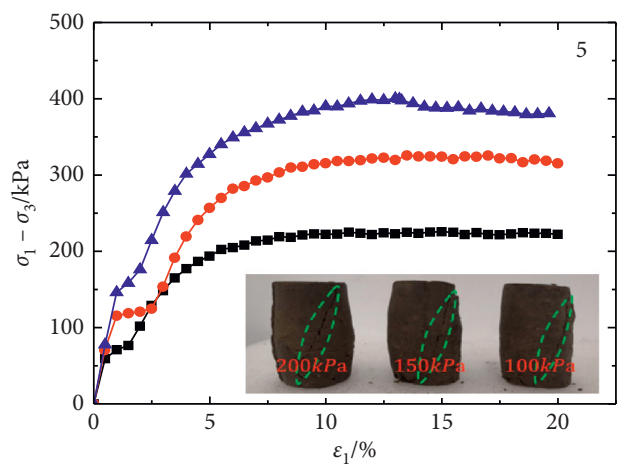

$\rightarrow-100 \mathrm{kPa}$

$\rightarrow 150 \mathrm{kPa}$

- $200 \mathrm{kPa}$

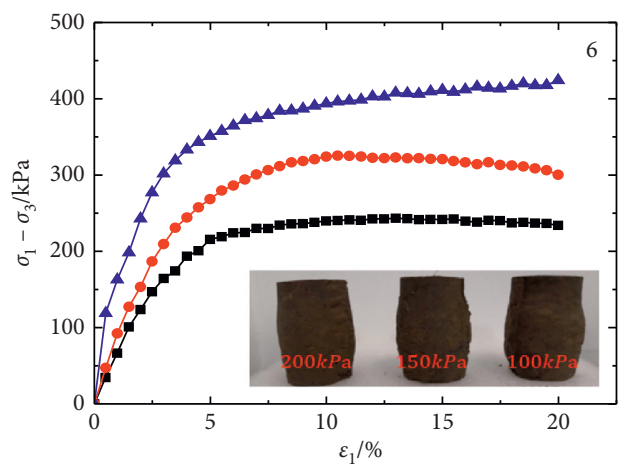

$\rightarrow-100 \mathrm{kPa}$

$\rightarrow 150 \mathrm{kPa}$

- $200 \mathrm{kPa}$

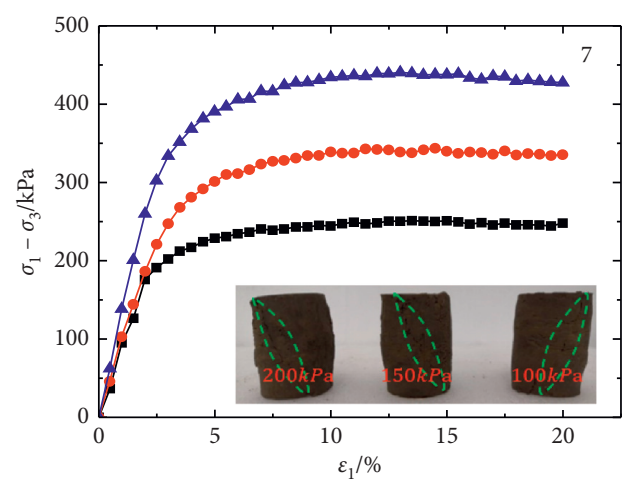

$\rightarrow-100 \mathrm{kPa}$

$\rightarrow 150 \mathrm{kPa}$

$-200 \mathrm{kPa}$

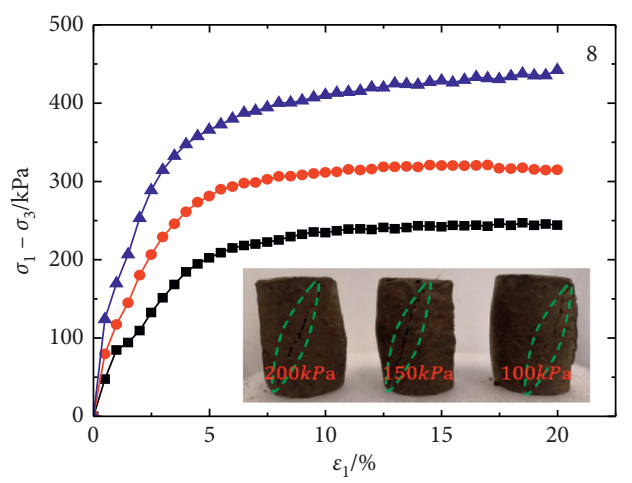

$\because-100 \mathrm{kPa}$
$\rightarrow-150 \mathrm{kPa}$

$-100 \mathrm{kPa}$

$\rightarrow 150 \mathrm{kPa}$

- $200 \mathrm{kPa}$

Figure 8: The stress-strain relation of the soil samples under different conditions. 


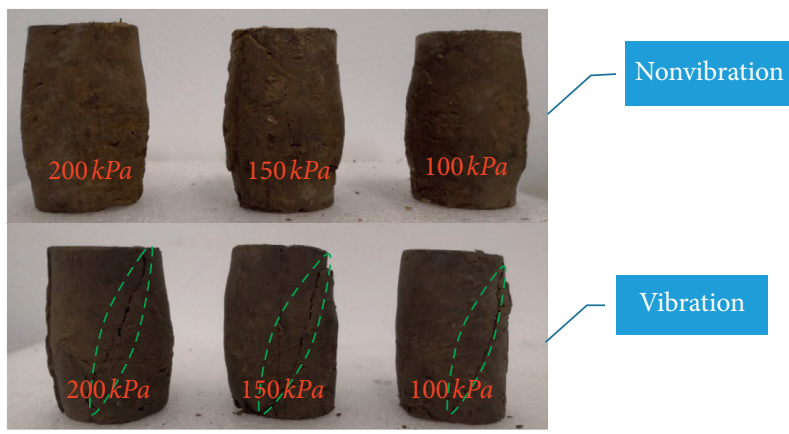

Figure 9: Macroscopic shear failure type of the soil samples.

TABLE 5: Soil parameters under different working conditions.

\begin{tabular}{lcccc}
\hline \multirow{2}{*}{$\begin{array}{c}\text { Intercept cohesion } \\
c(\mathrm{kPa})\end{array}$} & $\begin{array}{c}\text { Internal friction angle } \\
\varphi\left({ }^{\circ}\right)\end{array}$ & \multicolumn{2}{c}{ Compactness/\% } \\
\hline 1 & 26.9 & 27.4 & 88.2 & Before vibration \\
2 & 23.6 & 28.9 & 88.3 & 88.2 \\
3 & 21.3 & 27.7 & 88.2 & 88.2 \\
4 & 18.4 & 27.8 & 88.3 & 87.9 \\
5 & 16.1 & 27.8 & 88.3 & 88.2 \\
6 & 22.7 & 27.2 & 88.4 & 88.2 \\
7 & 18.0 & 29.1 & 88.3 & 88.0 \\
\hline
\end{tabular}

that the bearing capacity of the soil nail recovered after the vibration.

It is observed in Figure 13(c) that the loss of the pullout force of the nail was higher during vibration than after vibration. The loss of the pullout force of the nail during vibration consisted of two parts. In the first part, vibration acceleration occurred, causing a temporary "weightlessness" of the soil at the nail interface, reducing the pressure on the nail, and causing a loss of the nail-soil interface strength. In the second part, the vibration caused loosening at the interface between the nail and the soil the destruction of the nail-soil interface, as well as a reduction in the roughness of the nail-soil interface, resulting in the loss of the nail-soil interface strength. This response was verified by the reduction in the nail pullout force after vibration. The pullout force of the nail after vibration was primarily affected by the destruction of the nail-soil interface structure. The ratio of the pullout force after vibration to that during vibration showed that, regardless of the excitation forces, the loss of the nail pullout force after vibration accounted for more than $50 \%$ of the loss of the nail pullout force during vibration. Since the loss after vibration was mainly caused by the structural damage of the nail-soil interface, it can be concluded that the loss caused by structural damage was greater than the loss caused by acceleration.

Therefore, the loss of the pullout force of the nail was greater during vibration than after vibration. In addition, since the strength loss of the nail-soil interface during vibration was affected by acceleration, the acceleration increased with an increase in the excitation force. Therefore, the influence of the excitation force on the strength of the nail-soil interface during vibration was stronger than that after vibration. The strength loss of the nail-soil interface after vibration was mainly affected by the damage of the nailsoil interface structure.

As shown in Figure 14, corresponding prepullout force was given to the end of the nail under the overburden pressure of $80 \mathrm{kPa}$, and the variation of the maximum pullout force was studied under different excitation frequencies. Figures 14(a) and 14(b) showed the variation trend of $F_{n \text {-during }}$ and $F_{n \text {-after }}$ under different excitation frequencies. Figure 14(c) showed the ratio of the change of $F_{n \text {-during }}$ and $F_{n \text {-after }}$ to the initial prepullout force, respectively, and the ratio of $F_{n \text {-after }}$ to $F_{n \text {-during. }}$.

The pullout force curves of the nail at different frequencies are shown in Figures 14(a) and 14(b). The pullout force of the nail decreased substantially with the increase in the vibration time at a high excitation frequency; that is, the nail-soil interface strength decreased greatly. The higher the excitation frequency was, the greater the vibration damage to the interface strength of the nail was. The interaction between the nail and the soil decreased; thus, the pullout force of the nail decreased. Moreover, as the excitation time increased, the attenuation rate of the pullout force of the nail gradually decreased and then stabilized, indicating that the vibration at this frequency did not affect the nail-soil interface all the time and reached an equilibrium state.

As shown in Figure 14(c) at different vibration frequencies, the loss of the pullout force of the nail was greater during vibration than after vibration. The curve of the ratio of the pullout force loss after vibration and during vibration 


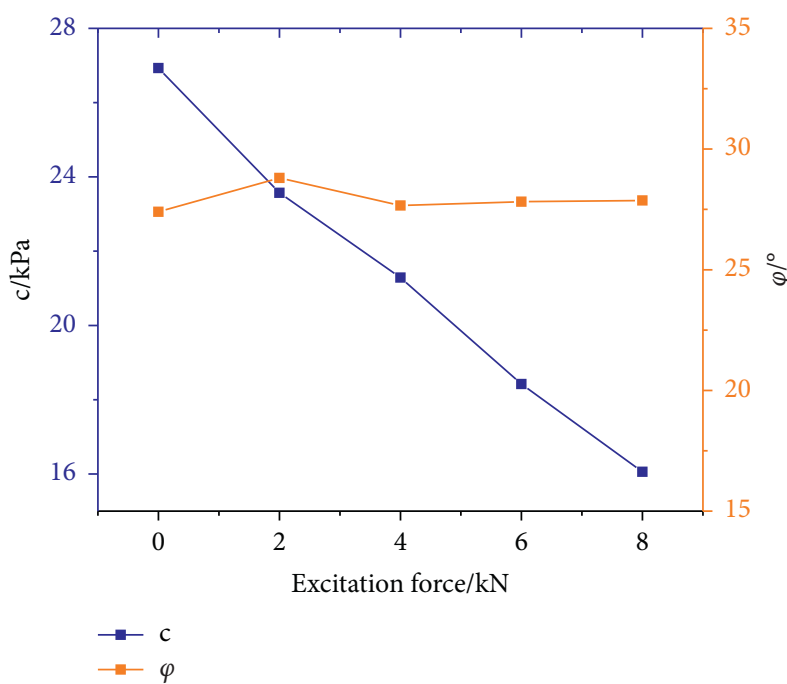

(a)

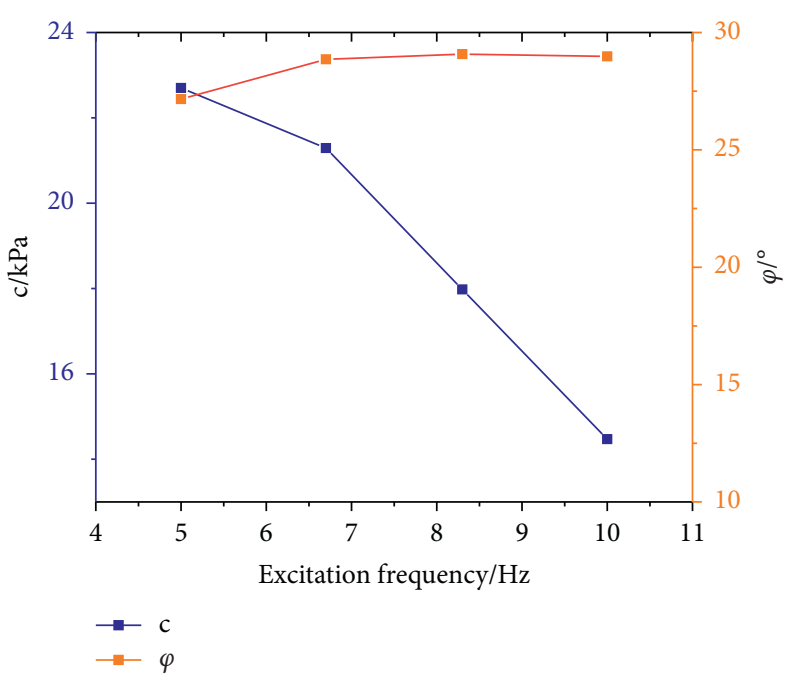

(b)

FIGURE 10: Soil strength parameters under different excitation conditions. (a) Excitation force. (b) Excitation frequency.

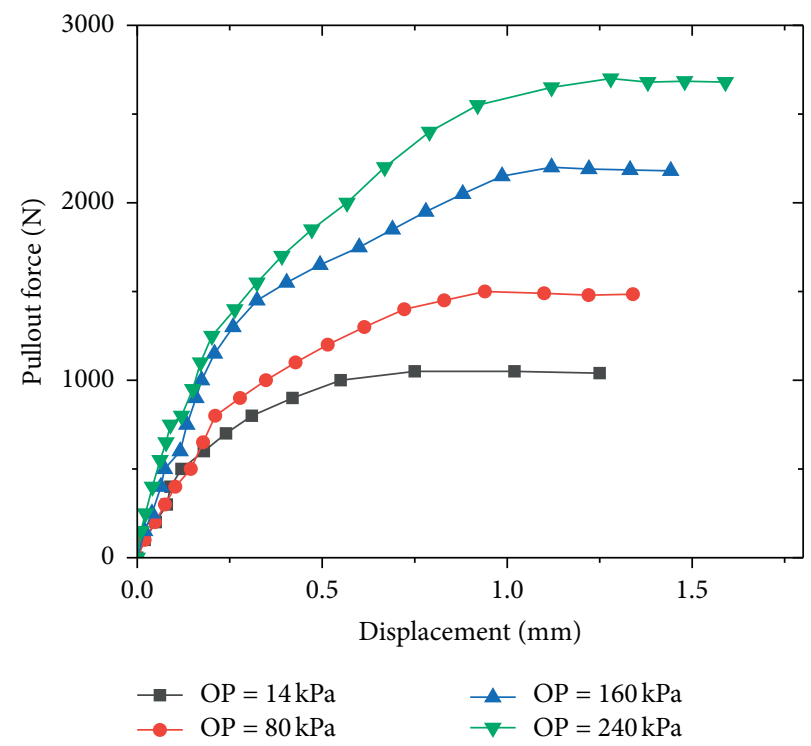

Figure 11: Curves of displacement of nail head with pullout load.

shows that the loss of the pullout force after vibration accounted for more than $50 \%$ of that during vibration at different vibration frequencies. This result indicated that the loss of the pullout force caused by structural failure of the nail-soil interface was greater than that caused by acceleration.

\section{Effects of Pile-Driving Vibration on Soil- Nailing-Reinforced Slopes}

5.1. Influence of the Reduction of $c$ on the Axial Force of the Soil Nail. The paper made the following analysis assumptions: (1) no displacement occurs at the base of the soil nail wall; (2) the distribution of shear stress on the soil nails is uniform; (3) the slide of the foundation pit is wedge-shaped; the bending and shear stress of the soil nail are not considered, and the unstable soil mass does not rotate; (4) only one soil nail passes through the failure surface; (5) the Coulomb criterion applies on the failure surface $B C$.

As shown in Figure 15, it is assumed that the lateral width of the unstable soil mass is $1 \mathrm{~m}$, and $f$ is the cohesive contribution of shear strength [29]. $G$ is the weight of the potentially unstable soil mass; $T$ is the axial force of the nail on the slip surface; $\alpha$ is the dip angle between the soil nail and the horizontal plane, and $R$ is the reaction force on the failure surface $B C ; \theta$ is the angle of the failure surface $B C ; \varphi$ refers to the internal friction angle of the soil.

According to the force vector polygon, we have the following:

Horizontal equilibrium equation: 


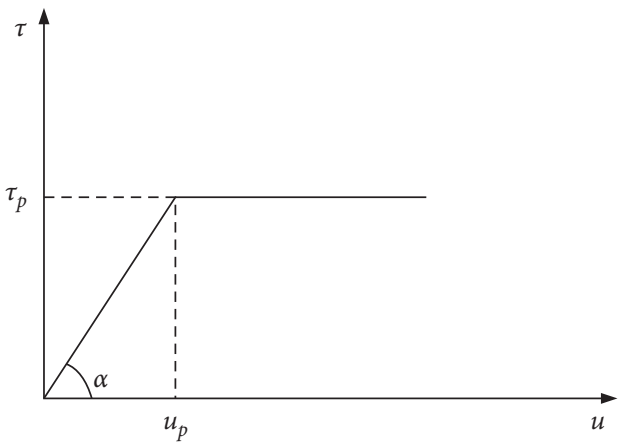

FIGURE 12: Relationship between the shear stress and the relative displacement of the soil nail.

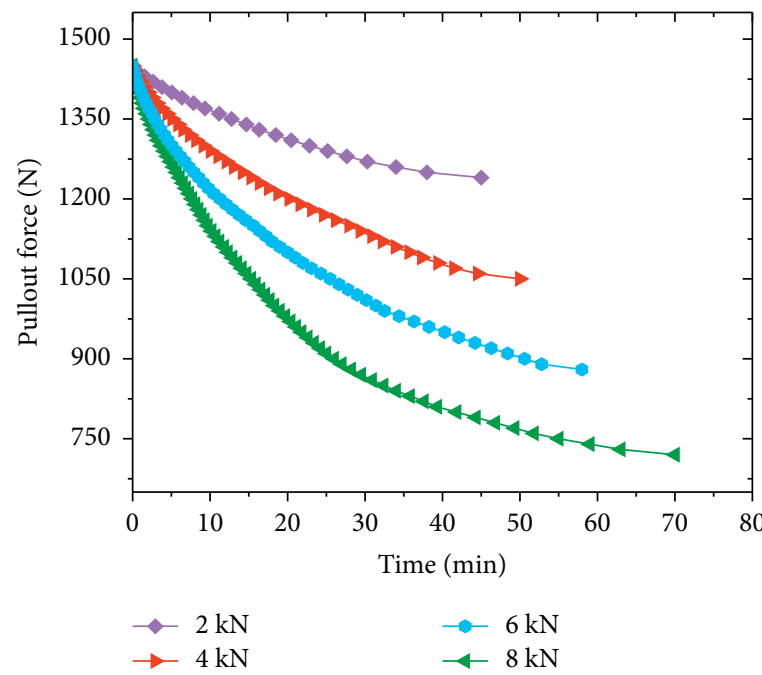

(a)

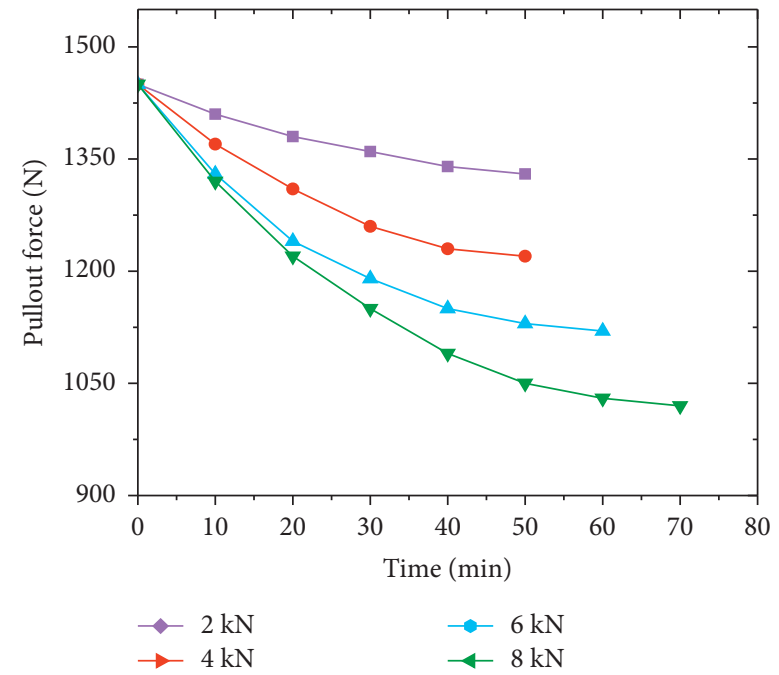

(b)

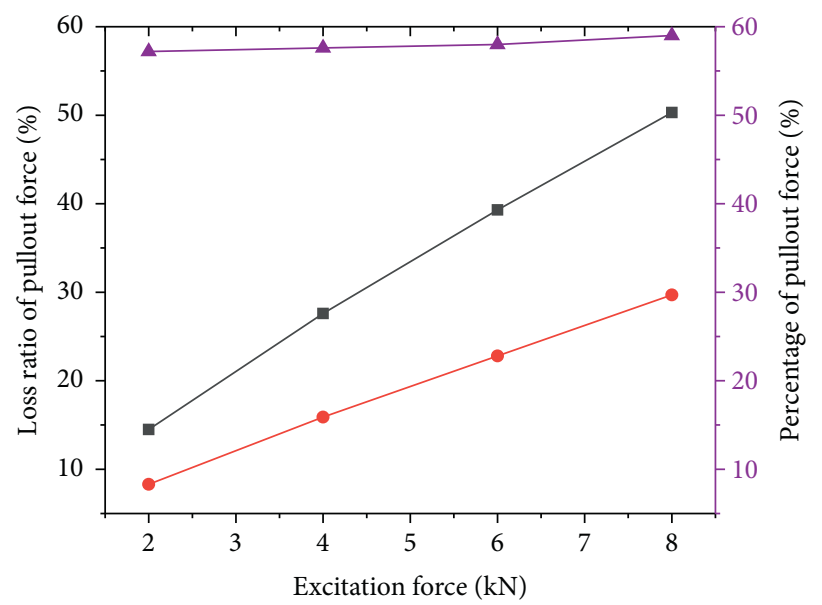

$\_$The ratio of $F_{n \text {-after }}$ to $F_{n \text {-during }}$
- During vibration
$\rightarrow$ After vibration

(c)

Figure 13: The variation of pullout force with time under different excitation forces. (a) During vibration. (b) After vibration. (c) Loss ratio of pullout force $\left({ }^{*}\right.$ the ratio of the change of the pullout force to the initial prepullout force). 


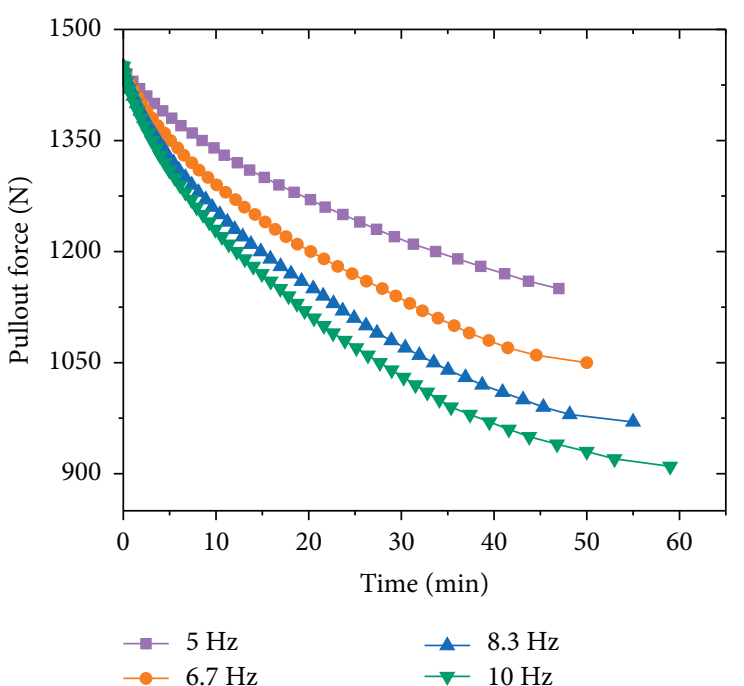

(a)

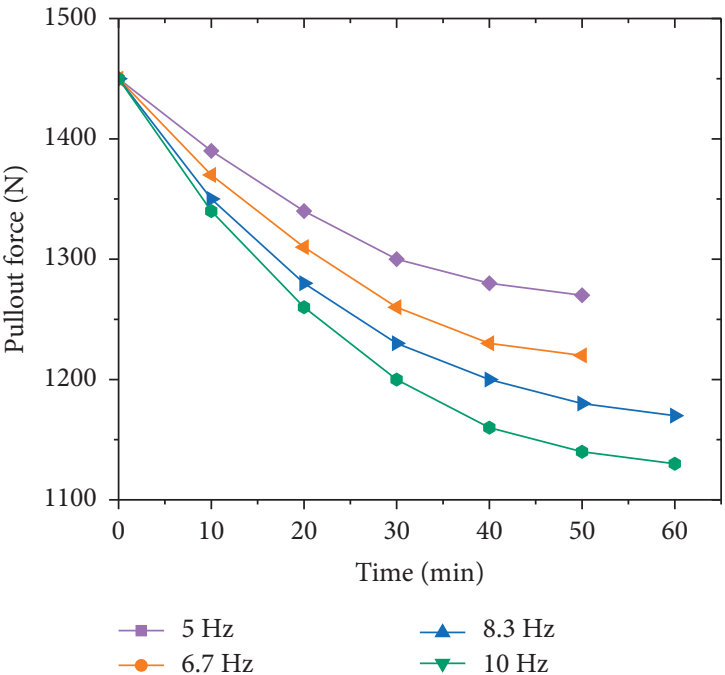

(b)

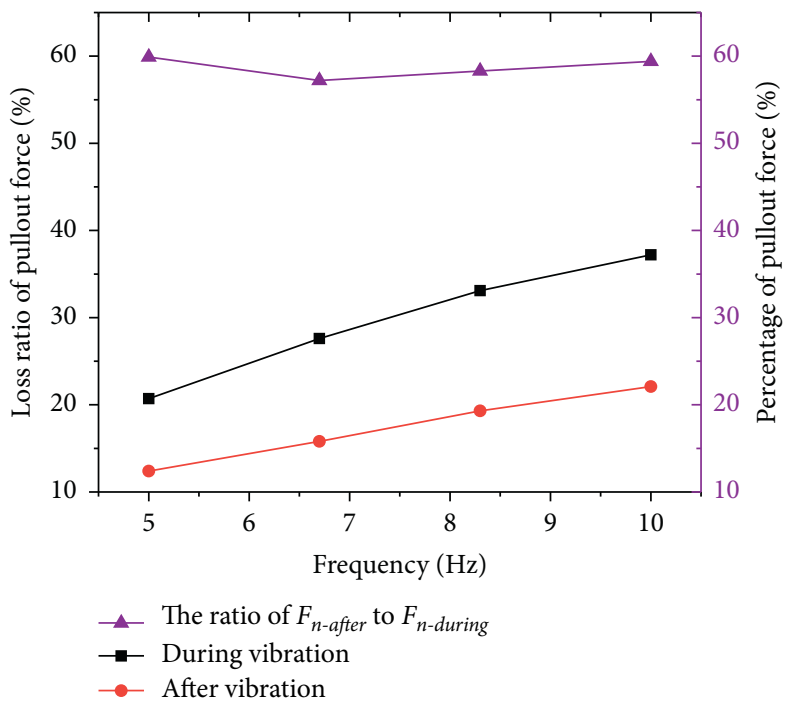

(c)

FIGURE 14: The variation of pullout force with time under different excitation frequencies. (a) During vibration. (b) After vibration. (c) Loss ratio of pullout force.

$$
f \cos \theta+T \cos \alpha=R \sin (\theta-\varphi) .
$$

Vertical equilibrium equation:

$$
f \sin \theta+R \cos (\theta-\varphi)=G+T \sin \alpha .
$$

Given equations (2) and (3), the following simplification can be made:

$$
T=\frac{G-f(\sin \theta+\cos \theta \cos (\theta-\varphi))}{\cos (\theta-\varphi) \cos \alpha-\sin \alpha \sin (\theta-\varphi)} \sin (\theta-\varphi),
$$

where

$$
f=\frac{c H}{\sin \theta},
$$

where $c$ is the soil intercept cohesion, $\mathrm{Pa} ; H$ is the height of the foundation pit, $m ; \theta$ is the dip angle of the failure surface, $45+\varphi / 2^{\circ}$.
The test result indicated that $c$ decreased and $\varphi$ remained unchanged after vibration. The decrease in $c$ caused a decrease in the resistance $f$. Equation (5) indicates that $T$ increases to $T^{\prime}$ as $c$ decreases.

The resistance $R(x)$ of the soil nail was determined by the failure of the soil nail under tensile and the failure of the soil nail to pull out from the stable or unstable soil. In Figure 16 [30], $R_{T}$ is the tensile strength, $R_{F}$ is the pullout capacity, $R_{F}$ is the tensile force on the end of the soil nail, and $L$ is the length of the soil nail. Generally, factors affecting changes in the soil behavior do not affect the tensile strength of the soil nail reinforcement; that is, the resistance determined by the tensile strength of soil nail reinforcement is not affected by soil property changes. Therefore, only the reduction in the nail resistance caused by a reduction in $\tau_{p}$ was considered in the analysis of the soil nail resistance. The change in the soil nail resistance due to soil behavior variation is shown in Figure 16. 
The resistance of the nail changed from $R(x)$ to $R^{\prime}(x)$ as the nail-soil interface $\tau_{p}$ decreased. It is assumed that the soil behavior changes in the entire range of the support. Since the maximum value of the soil nail force and the stability of the nearby soil are most sensitive to changes, it was assumed that the antislide contribution of the soil nail was the largest after the decrease of $c$. In other words, the reduction in the failure surface resistance caused by the reduction in $c$ was compensated for by an increase in the soil nail force, resulting in a change in the nail force. As shown in Figure 16, the axial tension of each section of the soil nail changed from $T(x)$ to $T^{\prime}(x)$.

5.2. Influence of the Reduction in c and $\tau_{p}$ on the Displacement of the Soil Nail. The soil nail can be passively stressed only after the soil has been displaced. The constraint of the soil nail on the soil can be compensated for by the soil deformation. As the axial force of the soil nail increases, the shear stress along the length of the soil nail and the displacement between the nail and the soil also change.

The nail axial force increased due to the vibration, and the nail-soil interface shear stress was redistributed. The process changed the working length of the soil nail. However, within the scope of the bearing capacity of the soil nail, its length was limited, when the working length was equal to the length of the soil nail. If the axial force continued to increase, it was beyond the bearing capacity of the soil nail.

The soil nail in the active zone was in the working state. When the interface shear stress of the nail reached the interface strength, its shear force did not increase, and the shear stress caused by vibration in the active zone was transferred to the surface layer [31].

When the shear stress of the nail-soil interface in the stable region reached the interface strength, the working length of the soil nail increased.

As shown in Figure 16, the nail bears the tensile $R_{F}$ that the surface exerts on the nail head and the shear resistance; the direction of the force is toward the foundation pit and the outside of the foundation pit. The axial force distribution of the soil nail is depicted in the dotted line in Figure 17. Here, the paper simplified the axial force distribution of the soil nail as a straight line (the solid line).

Therefore,

$$
T=\tau \pi d_{0} L
$$

In conjunction with equations (5)-(7), the working length of the soil nail in the stable area can be obtained as follows:

$$
L_{a}=\frac{G-f(\sin \theta+\cos \theta \cos (\theta-\varphi))}{\cos (\theta-\varphi) \cos \alpha-\sin \alpha \sin (\theta-\varphi)} \times \frac{\sin (\theta-\varphi)}{\tau_{a} \pi d_{0}} .
$$

Under the influence of vibration, the axial force of the soil nail increased to $T^{\prime}$. As the axial force of the soil nail increased, the shear resistance of the soil nail and the relative displacement of the soil nail and the soil increased.

The deformation $\delta_{1}$ of $L_{a}$ of the soil nail in the stable area under the axial force is

$$
\delta_{1}=\int_{0}^{L_{a}} \frac{T^{\prime} / L_{a} x}{E A} d x=\frac{T^{\prime} L_{a}}{2 E A}=\left(\frac{G-f(\sin \theta+\cos \theta \cos (\theta-\varphi))}{\cos (\theta-\varphi) \cos \alpha-\sin \alpha \sin (\theta-\varphi)}\right)^{2} \times \frac{\sin ^{2}(\theta-\varphi)}{2 E A \tau_{a} \pi d_{0}}
$$

where $L_{a}$ is the length of the nail in the stable area, $E$ is the elasticity modulus of the nail, and $A$ is the cross-sectional area of the nail.

Within the ultimate bearing capacity of the soil nail, the shear stress at the interface is uniformly distributed along the length $L_{a}$ of the stable area. If the shear value $\tau$ is known, the corresponding shear $\tau$ and the shear displacement $u$ of the nail and the surrounding soil are determined by the two following methods:

$$
\begin{gathered}
\tau^{\prime}=\frac{T^{\prime}}{\pi d_{0} L_{a}}, \\
u=\frac{\tau^{\prime}}{k}=\frac{T^{\prime}}{k \pi d_{0} L_{a}},
\end{gathered}
$$

where $k$ is the shear deformation coefficient, which can be determined by experiments or based on experience; $d_{0}$ is the cross-sectional diameter of the soil nail.

Because the surface exerts a certain tensile force on the nail head and the stiffness of the soil nail in the active area of the soil nail is much greater than that of the stable area, the deformation $\delta_{2}$ of $L_{f}$ can be obtained by equation (9). The error caused by the deformation calculation can be ignored.

$$
\delta_{2}=\frac{T^{\prime} L_{f}}{E A}=\frac{G-f(\sin \theta+\cos \theta \cos (\theta-\varphi))}{\cos (\theta-\varphi) \cos \alpha-\sin \alpha \sin (\theta-\varphi)} \frac{\sin (\theta-\varphi) L_{f}}{E A}
$$




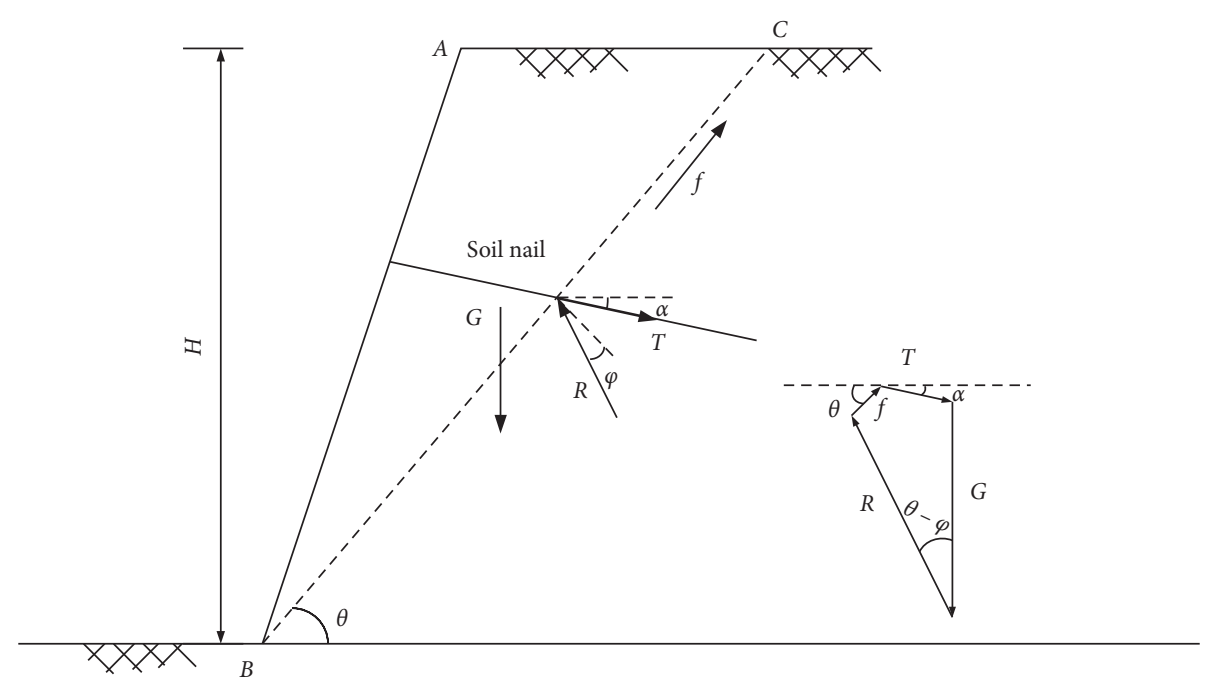

FIGURE 15: Forces acting on the soil wedge.

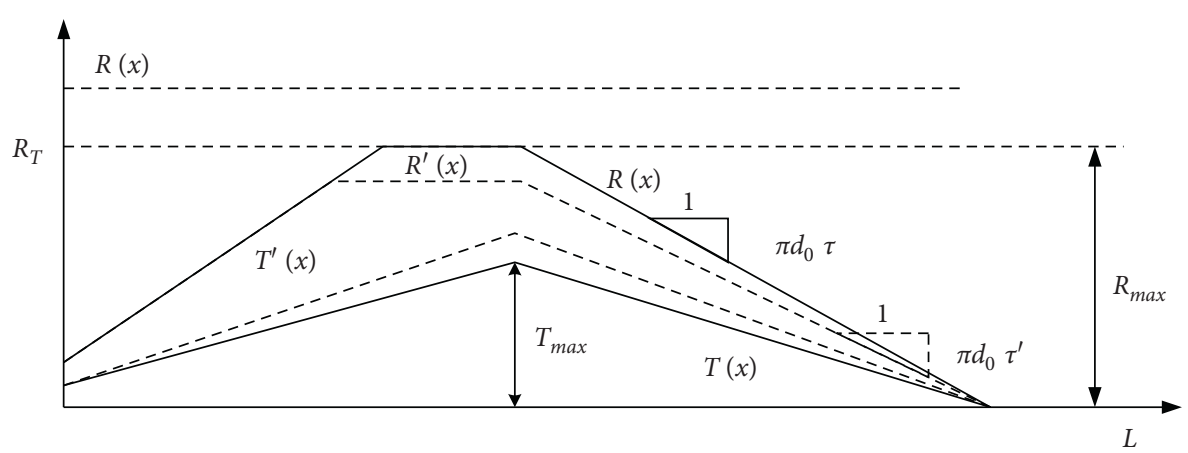

(a)

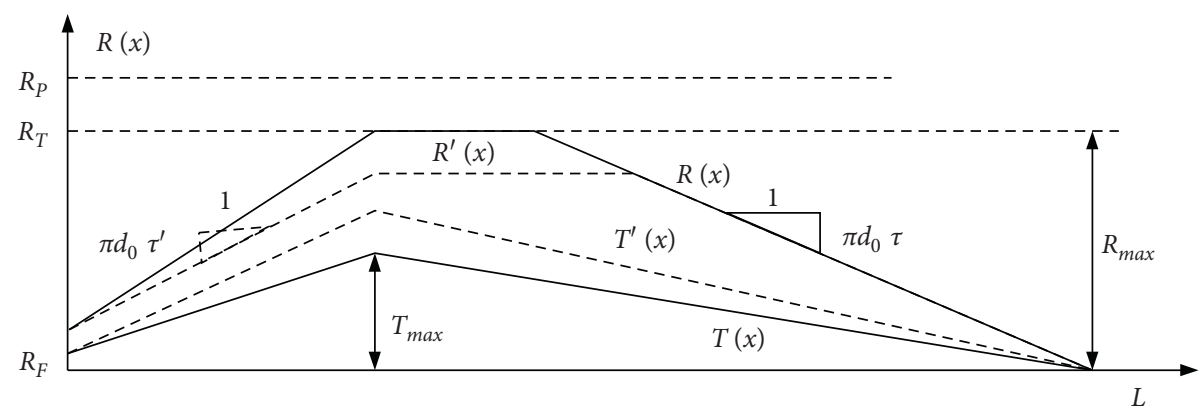

(b)

FIGURE 16: Variation of nail force and resistance with the variation of soil behavior. (a) Resistance is controlled by pullout failure of the stable soil mass. (b) Resistance is controlled by pullout failure of the unstable soil mass.

where $L_{f}$ is the length of the nail in the active area.

The total displacement of the soil nail is as follows:

$$
\begin{aligned}
\delta= & \delta_{1}+\delta_{2}+u=\left(\frac{G-f(\sin \theta+\cos \theta \cos (\theta-\varphi))}{\cos (\theta-\varphi) \cos \alpha-\sin \alpha \sin (\theta-\varphi)}\right)^{2} \frac{\sin ^{2}(\theta-\varphi)}{2 E A \tau_{a} \pi d_{0}} \\
& +\frac{G-f(\sin \theta+\cos \theta \cos (\theta-\varphi))}{\cos (\theta-\varphi) \cos \alpha-\sin \alpha \sin (\theta-\varphi)} \frac{\sin (\theta-\varphi) L_{f}}{E A}+\frac{\tau^{\prime}}{k} .
\end{aligned}
$$




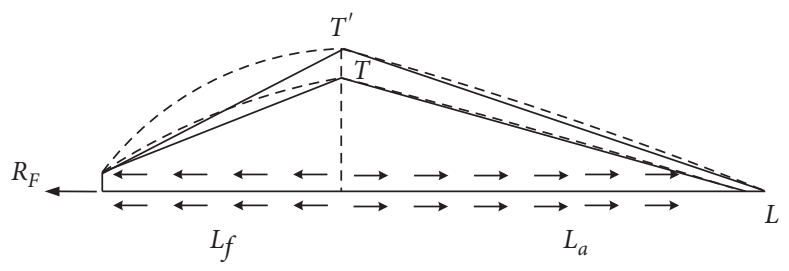

FIGURE 17: Force acting on the soil nail.

Therefore, the vibration of pile-driving increases the axial force and displacement of the soil nail.

The shear stress between the soil nail and the soil is directly proportional to the relative displacement of the nail. When the relative displacement reaches a certain value, the shear stress reaches the interface strength, as shown in Figure 12.

$$
\begin{aligned}
& \tau_{x}=k u_{x} \quad\left(u_{x}<u_{p}\right), \\
& \tau_{x}=k u_{p}=\tau_{p} \quad\left(u_{x} \geq u_{p}\right),
\end{aligned}
$$

where $\tau_{p}$ is the nail-soil interface strength; $u_{p}$ is the minimum relative displacement when the interface strength has been reached; $u_{x}$ is the displacement at the $x$ section of the soil nail; $k$ is the shear deformation coefficient, which is related to the soil properties, the vertical stress in the upper part of the soil nail, and other factors.

As $c$ and $\tau_{p}$ decrease, the difference between the nail force and resistance decreases. When the axial force of a section of the soil nail equals the resistance, the soil nail force of this section reaches an extreme value, and the soil nailing support enters the failure stage. It is observed in Figure 17 that the displacement of the soil nail plays a decisive role in the distribution of the soil nail shear stress. The reduction in the nail-soil interface strength $\tau_{p}$ reduces the ultimate bearing capacity of the soil nail and the relative displacement when the shear stress reaches the interface strength, reducing the ability of the soil nail to resist displacement and deformation.

The decreases in $c$ and $\tau_{p}$ led to a reduction in the soil nail resistance and an increase in the deformation and displacement of the soil nailing support. Through deformation coordination, the relative displacement between the soil and nail increased, the axial force of the soil nail increased, the shear stress was redistributed, and the soil nailing support reached equilibrium and stable state again. However, with the decrease in $c$ and $\tau_{p}$, the resistance of the soil nail and the safety factor of the foundation pit were reduced, and the soil nailing support was more likely to change from a stable to an unstable state. Therefore, the vibration load of pile-driving reduced the ability of the soil nailing support to resist displacement and deformation, accelerating the process from stability to failure of the soil nailing support.

\section{Conclusions}

The soil strength and nail-soil interface strength under different vibration conditions were analyzed in laboratory model tests. Although no quantitative analysis was performed, the influence mechanism of the pile-driving vibration load on the soil nailing support system was qualitatively analyzed according to the test results. The main conclusions were as follows:

(1) The soil strength decreased under the influence of vibration. The stronger the excitation force was and the higher the frequency was, the greater the attenuation of the soil strength was. The influence of vibration on the soil was primarily manifested as soil failure, a significant decrease in the soil intercept cohesion $c$, and a negligible variation in the internal friction angle $\varphi$.

(2) The nail-soil interface strength was reduced by the vibration. The stronger the excitation force was and the higher the frequency was, the greater the attenuation of the nail-soil interface strength was. The larger the OP was, the smaller the nail-soil interface strength attenuation was.

(3) The nail-soil interface strength during vibration was mainly affected by the roughness changes due to structural failure and interface loosening caused by vibration acceleration. The soil-nail interface strength after vibration was primarily affected by changes in the interface roughness due to the decrease of interface strength. When the vibration acceleration was less than $0.1 \mathrm{~g}$, the pullout force loss caused by the failure of the nail-soil interface structure was greater than that caused by vibration acceleration.

(4) The reduction in the soil intercept cohesion $c$ and the nail-soil interface strength $\tau_{p}$ increased the axial force and displacement of the soil nail and reduced the resistance of the soil nail to displacement and deformation.

\section{Data Availability}

The data used to support the findings of this study are available from the corresponding author upon request.

\section{Conflicts of Interest}

The authors declare that they have no conflicts of interest.

\section{Acknowledgments}

This research was supported by the National Natural Science Foundation of China (no. 50978235). 


\section{References}

[1] D.-S. Kim and J.-S. Lee, "Propagation and attenuation characteristics of various ground vibrations," Soil Dynamics and Earthquake Engineering, vol. 19, no. 2, pp. 115-126, 2000.

[2] M. H. Hussein, W. A. Woerner, M. Sharp, and C. Hwang, "Pile driveability and bearing capacity in high-rebound soils," GeoCongress, vol. 4, 2006.

[3] E. Conte, A. Troncone, and M. Vena, "Behaviour of flexible piles subjected to inclined loads," Computers and Geotechnics, vol. 69, pp. 199-209, 2015.

[4] C. L. Ramshaw, A. R. Selby, and P. Bettess, Computation of the Transmission of Waves from Pile Driving in Ground Dynamics and Man-Made Processes, pp. 115-128, London, UK, 1998.

[5] M. E. Mabsout, S. M. Sadek, and T. E. Smayra, "Pile driving by numerical cavity expansion," International Journal for $\mathrm{Nu}$ merical and Analytical Methods in Geomechanics, vol. 23, no. 11, pp. 1121-1140, 1999.

[6] K. P. Mahutka, J. Grabe, and F. Konig, "Numerical modelling of pile jacking, driving and vibratory driving," in Proceedongs of the International Conference On Numerical Simulation Of Construction Processes In Geotechnical Engineering For Urban Environment, pp. 235-246, Bochum, Germany, February 2006.

[7] S. Henke and J. Grabe, "Simulation of pile driving by 3-dimensional Finite-Element analysis," in Proceedings of the 17th European Young Geotechnical Engineers' Conference, pp. 215-233, Zagreb, Croatia, July 2006.

[8] S. Henke, "Influence of pile installation on adjacent structures," International Journal for Numerical \& Analytical Methods in Geomechanics, vol. 34, no. 11, pp. 1191-1210, 2010.

[9] S. Hanna, I. Juran, O. Levy, and A. Benslimane, "Recent developments in soil nailing-design \& practice," Journal of Engineering and Applied Science, vol. 81, pp. 259-284, 1998.

[10] Y. J. Li, Y. Y. Xia, and Z. D. Wang, "Post-seismic displacement analysis of soil-nailed slope under earthquake," Rock and Soil Mechanics, vol. 41, no. 9, pp. 3013-3021, 2020.

[11] P. E. Cotton, M. David, and R. D. Luark, "Seismic response and extended life analysis of the deepest top-down soil nail wall in the U.S.," in Proceedings of the GeoSupport 2004: Innovation and Cooperation in the Geo-Industry, pp. 723-740, Orlando Florida, USA, January 2004.

[12] M. Zhang, Q. Lv, and C. Wang, "Shaking table test for aseismic behavior of the soil-nail supporting system," Journal of Beijing University of Technology, vol. 37, no. 6, pp. 822-827, 2011.

[13] W. B. Tang, "Dynamic response and deformation of soil nailing under dynamic load," M. S. thesis, Dept. Geotechnical Eng., Hunan Univ. of Technology, Hunan, China, 2014.

[14] F. C. Zhu, X. G. Liao, and J. H. Li, "Research on model test of soil nailed slope on unsaturated compacted soils under cyclic load," Chinese Journal of Rock Mechanics and Engineering, vol. 28, no. s1, pp. 2994-3000, 2009.

[15] J. H. Dong and Y. P. Zhu, "Parametric analysis on seismic behavior of highway slope protected by soil nailing retaining wall under earthquake," Journal of Xi An University of Architecture and Technology (Natural Science), vol. 39, no. 5, pp. 661-666, 2007.

[16] Z. L. Zhang, "The FEM analysis of composite soil nailed wall in construction process and earthquake action," M. S. thesis, Dept. Structural Eng., Lanzhou Univ. of Technology, Lanzhou, China, 2007.
[17] G. B. Wang, "The FEM analysis of soil nailing wall in construction process and earthquake action," M. S. thesis, Dept. Structural Eng., Lanzhou Univ. of Technology, Lanzhou, China, 2006.

[18] X. J. Yu, "Contrast research on dynamic behavior of transient stresses in soil nails," Journal of Hefei University of Technology (Natural Science), vol. 30, no. 11, pp. 1505-1508, 2007.

[19] X. M. Zeng, Y. H. Du, and S. M. Li, "Testing study of prototype and model comparison on resisting dynamical load with soil nail supporting," Chinese Journal of Rock Mechanics and Engineering, vol. 22, no. 11, pp. 1892-1897, 2003.

[20] J. H. Li, "Study on dynamic response and interaction of soil slope and its anchoring structure subjected to earthquake," D. S. thesis, Dept. Construction Building Eng., Chang'an Univ, Xi'an, China, 2015.

[21] China Planning Press, Standard for Geotechnical Test Method (GBT 50123-2019), China Planning Press, Beijing, China, 2019.

[22] Y. Liu, J. Y. Liu, Q. M. Zheng, and G. N. Ma, "Model test study of synergistic effect of anchor composite soil nailing," Rock and Soil Mechanics, vol. 37, no. s1, pp. 462-468, 2016.

[23] Z. R. Niu and G. Y. Lu, "Discussion on mechanism and effect of Rayleigh wave on soil subjected to impact loading," Rock and Soil Mechanics, vol. 30, no. 6, pp. 1583-1589, 2009.

[24] Q. Yang, M. Wang, M. T. Luan, and G. X. Liu, "Experimental research of correlation on static and dynamic strength of unsaturated silty clay," Rock and Soil Mechanics, vol. 31, no. 1, pp. 71-80, Jan. 2010.

[25] K. Sukmak, P. Sukmak, S. Horpibulsuk, A. Chinkulkijniwat, A. Arulrajah, and S. L. Shen, "Pullout resistance of bearing reinforcement embedded in marginal lateritic soil at molding water contents," Geotextiles and Geomembranes, vol. 44, no. 3 , pp. 475-483, 2016.

[26] J. H. Yin and L. J. Su, "An innovative laboratory box for testing nail pull-out resistance in soil," Geotechnical Testing Journal, vol. 29, no. 6, pp. 451-461, 2006.

[27] L. J. Su, H. J. Liao, and J. H. Yin, "Investigation on stress variation in soil surrounding a soil nail during installation and pull-out," Rock and Soil Mechanics, vol. 4, no. s1, pp. 124-128, 2011.

[28] C. Zhang, H. H. Zhu, Y. Zhou, and B. Shi, "Recent progress on experimental and theoretical research of soil nail pullout mechanism," Journal of Disaster Prevention and Mitigation Engineering, vol. 33, no. s1, pp. 138-146, 2013.

[29] X. J. Hu, "Improvement on Coulumb accurate solution of active earth pressure to cohesive soil," Chinese Journal of Geotechnical Engineering, vol. 28, no. 8, pp. 1049-1052, 2006.

[30] H. X. Guo, E. X. Song, and Z. Y. Chen, " $c-\varphi-\tau$ strength reduction method for internal stability of soil nailing," Chinese Journal of Geotechnical Engineering, vol. 30, no. s1, pp. 187191, 2008.

[31] W. H. Wei and X. M. Han, "Calculation method of inner force and displacement of soil-nailing wall considering deformation coordination," Chinese Journal of Rock Mechanics and Engineering, vol. 32, no. s1, pp. 2758-2763, 2013. 